\title{
An evaluation of the effect of $\mathrm{N}$ - Butylbromide in the form of suppository in augmentation of cervical dilatation during labour, a prospective study at a tertiary care center
}

\author{
Nishita Shettian ${ }^{1, *}$, Satish J. Shetty ${ }^{2}$ \\ ${ }^{\mathbf{1}}$ Assistant Professor, ${ }^{2}$ Professor, Dept. of Obstetrics and Gynecology, A. J. Institute of Medical Sciences Mangalore, Karnataka, \\ India
}

*Corresponding Author:

Email: drnishitafernandes@yahoo.com

Received: $2^{\text {nd }}$ April, 2018

Accepted: $13^{\text {th }}$ May, 2018

\begin{abstract}
Introduction: Labour is a multifactorial process. The perception of pain to a great extent depends on the duration of labour and prolonged labour sets in a viscious cycle of pain - fear - spastic cervix. This cycle has to be broken if delivery is to proceed satisfactorily leading to delayed or arrested labour. A prospective study was undertaken to assess the effectiveness of Hyoscine $\mathrm{N}$ - Butylbromide (suppository) in augmentation of cervical dilatation during labour and any adverse effects on the maternal and fetal outcome.

Materials and Methods: Prospective study on the effect of Hyoscine - N - Butylbromide (suppository) in augmentation of cervical dilatation during labour. Primigravidae admitted to the labour ward in A. J. Institute of Medical Sciences, Mangalore were included in the study based on a criteria.

The average age in the study group was $24.07 \pm 3.22$ years and in the control group was $24.63 \pm 3.0$ years. Mean duration of active phase of first stage of labour in the study group was $279.93 \pm 62.53$ minutes (4 hours 40 minutes \pm 62.53 minutes) while in the control group was $398.57 \pm 96.51$ minutes (6 hours 39 minutes \pm 96.51 minutes). The difference is statistically significant $(\mathrm{P}<0.05)$. The duration of labour was reduced by 2 hours 11 minutes in the study group and is statistically significant. $(\mathrm{P}<$ 0.05) There were no adverse effects of the drug on the fetus (Apgar score was comparable between both groups). There were no significant side effects of HNBB on the mother

Conclusion: Hyoscine $-\mathrm{N}-$ Butylbromide suppository is a new aid in the management of uncomplicated labour for a convenient shorter and safer physiological delivery making it more tolerable for the mother.
\end{abstract}

Keywords: N - Butylbromide, Suppository, Labour, Tertiary care center.

\section{Introduction}

Labour is a multifactorial process. The perception of pain to a great extent depends on the duration of labour and prolonged labour sets in a viscious cycle of pain - fear - spastic cervix. This cycle has to be broken if delivery is to proceed satisfactorily leading to delayed or arrested cervical dilatation forms one of the most important group. Considering the above known facts attempts to accelerate cervical dilatation and thereby shorten the duration of labour without jeopardizing maternal or fetal interests would seem warranted. It is only humane to prevent unduly prolonged labour and this can be done by hastening cervical dilatation by using pharmacological agents. Antispasmodic drugs are frequently used to overcome cervical spasm and reduce the duration of first stage of labour. In clinical use one of the most effective of these derivatives was found to be Hyoscine - N - Butylbromide. Hyoscine - N Butylbromide has a selective action on the cervico uterine plexus and when administered in the phase of cervical dilatation resulted in facilitated dilatation of the cervix and shortened the duration of labour making it more tolerable for the mother. It does not have any unfavourable side effects on the uterine contractions and on the fetus. Hyoscine - N - Butylbromide suppositories are of immense help because of convenience of administration and faster absorption. Available literature does not show many reports of the use of Hyoscine - N - Butylbromide in obstetric practice particularly for acceleration of labour. A prospective study was undertaken to assess the effectiveness of Hyoscine - N - Butylbromide (suppository) in augmentation of cervical dilatation during labour and any adverse effects on the maternal and fetal outcome.

\section{Materials and Methods}

A prospective study on the effect of Hyoscine - N - Butylbromide (suppository) in augmentation of cervical dilatation during labour. Primigravidae admitted to the labour ward in A. J. Institute of Medical Sciences, Mangalore were included in the study based on the following criteria. And taking consent from the ethical clearance committee and registering the study under drug trail the study was initiated.

Inclusion Criteria: Singleton pregnancy, Term gestation, cephalic presentation, No cephalopelvic disproportion, No obstetric or medical complications, spontaneous onset of labour, Active phase of labour intact fetal membranes. 
Exclusion Criteria: Multipara, Multiple pregnancy, fetal malpresentation, induced labour, cervical surgery in the past, hypertensive patient, known hypersensitivity to HNBB, patients on dopamine antagonists, beta adrenergic agents and tricyclic antidepressants.

The patients included in the study were divided into two groups:

Group A (Study group): were given $10 \mathrm{mg}$ of HNBB suppository when cervical dilatation was $2-3 \mathrm{~cm}$ and cervical effacement of $50 \%$ or more.

Group B (Control group): were not given any drug. The following parameters were monitored in both groups:

1. Progress of Labour with Partogram: Frequency and duration of uterine contractions were recorded every thirty minutes based on per abdominal examination. Cervical dilatation and effacement were recorded second hourly by per vaginal examination. Station and position of the presenting part were recorded second hourly by per vaginal examination.

2. Maternal Parameters: Pulse rate and respiratory rate were recorded at thirty minute intervals. Blood pressure was recorded at hourly intervals. Anticholinergic side effects like xerostomia, dyshydrosis, restlessness, flushing of face etc if any were recorded.

3. Fetal Parameters: Fetal heart rate was recorded every fifteen minutes by auscultation. Colour of the amniotic fluid was noted. Apgar score of the newborn were recorded at 1 and 5 minutes after birth. Newborn baby requiring NICU care if any was recorded.
Statistical analysis of the collected data was done using the chi-square test and a $\mathrm{P}$ value of $<0.05$ was considered significant.

\section{Observations and Analysis}

The average age in the study group was $24.07 \pm$ 3.22 years and in the control group was $24.63 \pm 3.0$ years. Mean duration of active phase of first stage of labour in the study group was $279.93 \pm 62.53$ minutes (4 hours 40 minutes \pm 62.53 minutes) while in the control group was $398.57 \pm 96.51$ minutes (6 hours 39 minutes \pm 96.51 minutes). The difference is statistically significant $(\mathrm{P}<0.05)$. The duration of second and third stage of labour were comparable between both the groups and difference was not statistically significant. The total duration of labour was $318.31 \pm 83.81$ minutes $(5$ hours 18 minutes \pm 83.81 minutes) in the study group as compared to $448.57 \pm 93.84$ minutes $(7$ hours 29 minutes \pm 93.84 minutes) in the control group. The duration of labour was reduced by 2 hours 11 minutes in the study group and is statistically significant. $(\mathrm{P}<0.05)$ Incidence of spontaneous vaginal delivery was higher in the study group as compared to the control group $(96.7 \%$ vs 93.3\% respectively) but is not statistically significant. There were no cases of postpartum haemorrhage or retained placenta in both the groups signifying that HNBB does not reduce the uterine tone in the period following delivery. There were no adverse effects of the drug on the fetus (Apgar score was comparable between both groups).

There were no significant side effects of HNBB on the mother.

Graph 1: Comparison of duration of active phase of first stage of labour (\%)

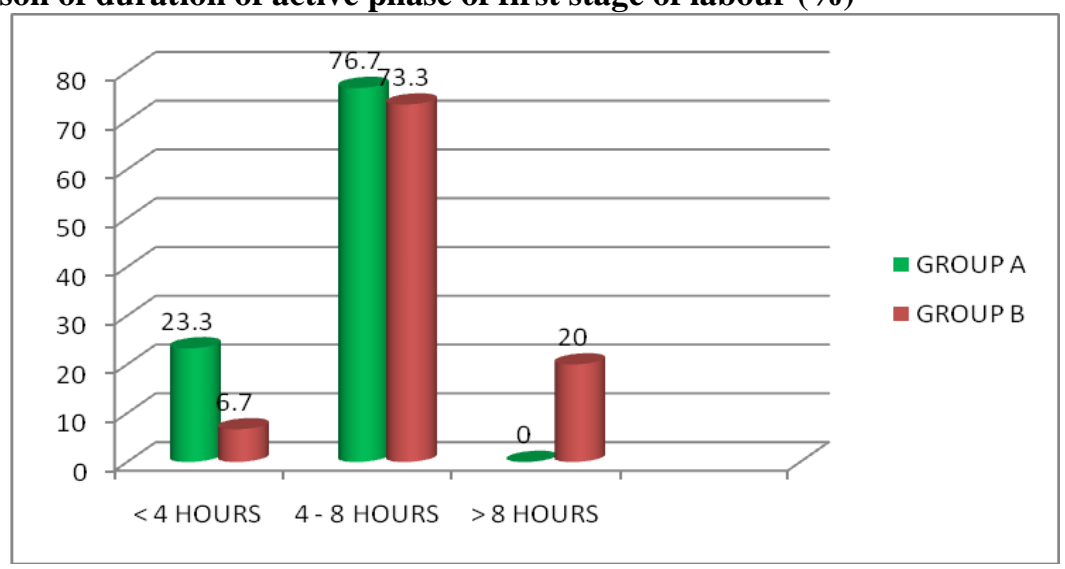


Graph 2: Comparison of duration of second stage of labour (\%)

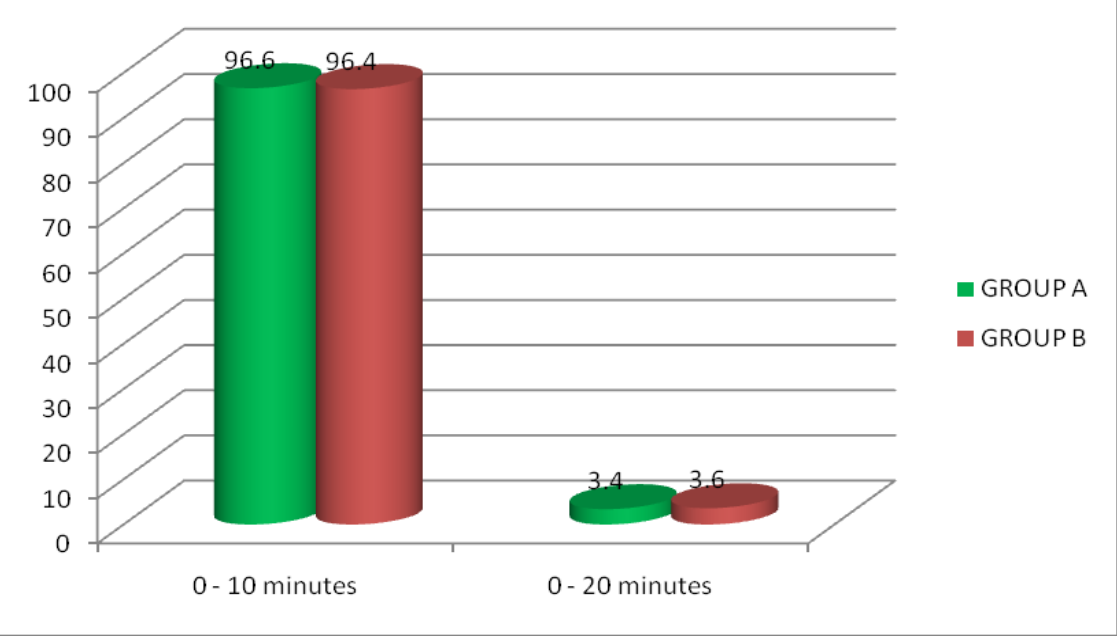

Graph 3: Comparison of duration of third stage of labour (\%)

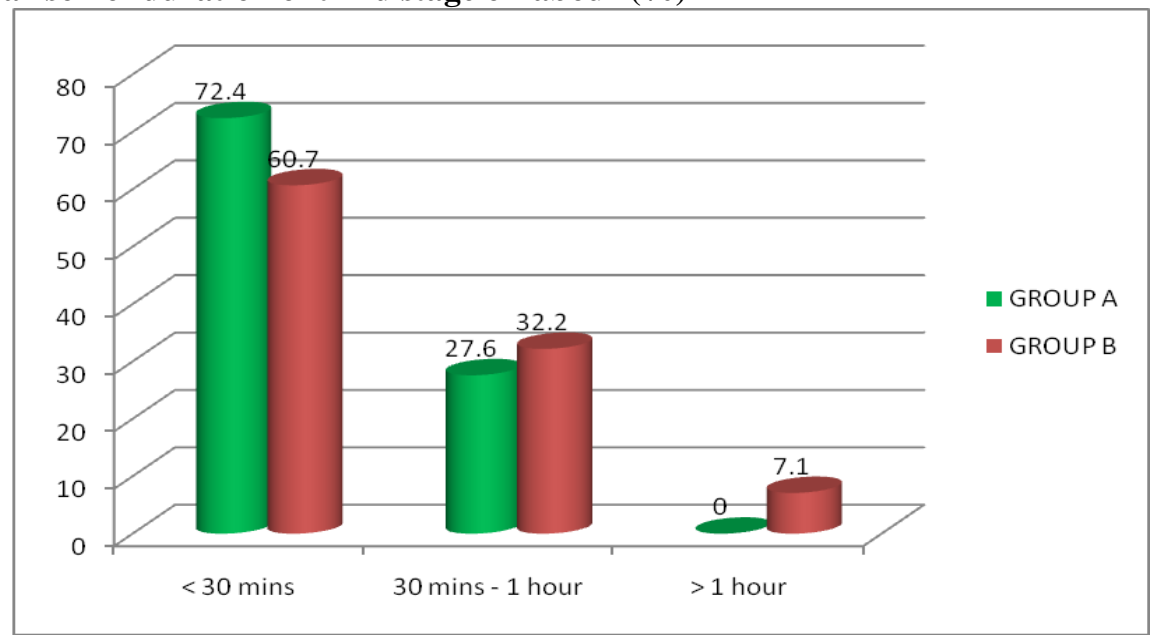

Graph 4: Total duration of labour (drug to delivery interval):

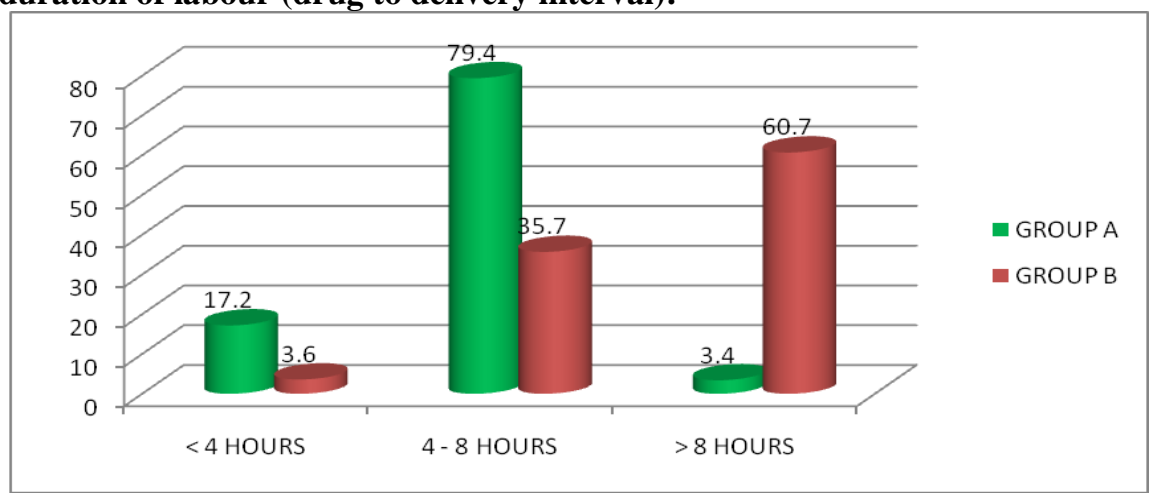

\section{Discussion}

For obstetricians present at delivery nothing is more disturbing than prolonged labour even though abnormal troublesome events may not accompany it. Protracted labour leads to exhaustion and increased psychic stress on the mother.

The dilatation of cervix is one of the effective end results of the forces of labour. Many a times it is observed that though there are good uterine contractions cervix fails to dilate or dilates slowly. According to different studies the muscle content of the cervix ranges from $5-20 \% .^{1-3}$ This is the physiological motivation of the fact that for augmenting cervical dilatation spasmolytic drugs can be used. 
Table 1

\begin{tabular}{|c|c|c|c|c|c|c|}
\hline \multirow{2}{*}{$\begin{array}{c}\text { Duration of } \\
\text { labour }\end{array}$} & \multicolumn{2}{|c|}{ Samal etal $^{4}$} & \multicolumn{2}{|c|}{ Bhattacharya \& Joshi $^{5}$} & \multicolumn{2}{|c|}{ Present study } \\
\hline & Group A & Group I & Group A & Group B & Group A & Group B \\
\hline$<8$ hours & $88 \%$ & $38 \%$ & $81 \%$ & $41 \%$ & $96.6 \%$ & $39.3 \%$ \\
\hline$>8$ hours & $12 \%$ & $62 \%$ & $19 \%$ & \multicolumn{2}{|r|}{$3.4 \%$} & $60.7 \%$ \\
\hline \multirow{2}{*}{\multicolumn{3}{|c|}{ Study }} & \multicolumn{4}{|c|}{ Average duration of labour } \\
\hline & & & \multicolumn{2}{|c|}{ Group A } & \multicolumn{2}{|c|}{ Group B } \\
\hline \multicolumn{3}{|l|}{ Samal etal ${ }^{4}$} & \multicolumn{2}{|c|}{5 hours 28 minutes } & \multicolumn{2}{|c|}{8 hours 10 minutes } \\
\hline \multicolumn{3}{|c|}{ Bhattacharya and Joshi $^{5}$} & \multicolumn{2}{|c|}{5 hours 13 minutes } & \multicolumn{2}{|c|}{8 hours 53 minutes } \\
\hline \multicolumn{3}{|l|}{ Present study } & 5 hours $18 \mathrm{mi}$ & & 7 hours 29 & nutes \\
\hline \multicolumn{3}{|l|}{ Study } & \multicolumn{4}{|c|}{ Average reduction in duration of labour } \\
\hline \multicolumn{3}{|l|}{ Samal et $\mathrm{al}^{4}$} & \multicolumn{4}{|c|}{2 hours 42 minutes } \\
\hline \multicolumn{3}{|c|}{ 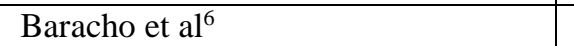 } & \multicolumn{4}{|c|}{2 hours 01 minutes } \\
\hline \multicolumn{3}{|l|}{ Present study } & \multicolumn{4}{|c|}{2 hours 11 minutes } \\
\hline \multirow{2}{*}{\multicolumn{3}{|c|}{ Study }} & \multicolumn{4}{|c|}{ Incidence of spontaneous vaginal delivery } \\
\hline & & & \multicolumn{2}{|c|}{ Group A } & \multicolumn{2}{|c|}{ Group B } \\
\hline \multicolumn{3}{|l|}{ Samal et $\mathrm{al}^{4}$} & \multicolumn{2}{|l|}{$96 \%$} & \multirow{2}{*}{\multicolumn{2}{|c|}{$\frac{92 \%}{80 \%}$}} \\
\hline \multicolumn{3}{|c|}{ Bhattacharya and Joshi ${ }^{5}$} & \multirow{2}{*}{\multicolumn{2}{|c|}{$\frac{90 \%}{88 \%}$}} & & \\
\hline \multicolumn{3}{|l|}{ Baracho etal ${ }^{6}$} & & & 80 & \\
\hline Present study & & & $96.7 \%$ & & 93. & \\
\hline
\end{tabular}

\section{Conclusion}

From this study it is evident that administration of Hyoscine - N - Butylbromide suppository significantly reduces the duration time of cervical dilatation in the active phase of first stage of labour, thereby reducing the total duration of labour and does not have unfavourable side effects on the uterine contractions. The drug is safe without any significant maternal or fetal side effects.

\section{References}

1. Buckingham JC, Buethe RA Jr, Danforth DN. Collagen - muscle ratio in clinically normal and clinically incompetent cervices. Am J Obstet and Gynec. 1965;91:235.

2. Hotwani J, Ainpure SS. Hyoscine Butylbromide suppositories. Indian Medical Gazette. 2000;7:217-219.

3. Corssen G. A study of the use and mode of action of the antispasmodic drug buscopan in gynaecology and obstetrics. Med Klin. 1953;48:1286-1288.

4. Samal S, Uma G, Wable M. Buscopan (Hyoscine - N Butylbromide) in acceleration of labor. Indian Medical Gazette. 1998:8-10.

5. Bhattacharya P, Joshi SG. Acceleration of labour intramuscular Buscopan injection. J Obstet and Gynae of India. 1985;35:1014-1017

6. Baracho HM, Kamat J.R, Kunkalekar K, Jacob L. Hyoscine-N-Butylbromide (Buscopan) in acceleration of labour. J Obstet and Gynae of India. 1984;34:509-512.

How to cite this article: Shettian N, Shetty SJ. An evaluation of the effect of $\mathrm{N}$ - Butylbromide in the form of suppository in augmentation of cervical dilatation during labour, a prospective study at a tertiary care center. Ind J Obstet Gynecol Res. 2018;5(3):357-360. 